\title{
IMPACT OF THERMAL STABILITY ON THE PERFORMANCE OF POLYMERS AS CALCIUM PHOSPHATE INHIBITORS FOR INDUSTRIAL WATER SYSTEMS
}

\author{
Zahid Amjad* \\ (*zahid.amjad@noveon.com) \\ Performance Coatings Group \\ Noveon, Inc., 9911 Brecksville Road \\ Brecksville, Ohio 44141, USA
}

Keywords: calcium phosphate, precipitation, inhibition, polymer thermal stability

\begin{abstract}
The impact of thermal stability on the performance of homo-, co-, and ter-polymers on the precipitation of calcium phosphate was investigated at $\mathrm{pH} 8.50,50^{\circ} \mathrm{C}$, calcium $=3.50 \mathrm{mM}$ and phosphate $=0.095$ mM. The polymers tested include: poly(acrylic acid), P-AA; poly(maleic acid), P-MA; poly(acrylic acid: 2 acrylamido-2-methyl propane sulfonic acid), P-AA:SA; P-AA:SA:t-bAm (ter-butylacrylamide), and P-AA:SA:SS (sulfonated styrene). It has been found that all polymers lose performance to a varying degree when exposed to thermal treatment. The performance data also suggest that SS containing ter-polymer is a better calcium phosphate inhibitor than t-bAm containing ter-polymer. In the case of co-polymer of AA:SA, the thermal treatment exhibits strong negative influence on the inhibitory power of polymer. The results have been explained in terms of loss of SA and $\mathrm{t}-\mathrm{bAM}$ in the co- and ter-polymers leading to the formation of poly(acrylic acid).
\end{abstract}

(Received January 14, 2006; Accepted July 24, 2006)

\section{INTRODUCTION}

Calcium phosphate scale formation in industrial water systems i.e., cooling, boiler, geothermal, and potable water production with reverse osmosis processes is a persistent problem ${ }^{1}$. Additionally, the formation of calcium phosphates is an important process in physiological situations such as formation of pathological stones, teeth and bones. The deposition of calcium phosphate on heat exchanger surfaces have been reported during the pasteurization of milk. In industrial water processes the insulating nature of calcium phosphate scale on equipment surfaces results in decreased system efficiency and premature equipment failure. Factors influencing the precipitation of calcium phosphate in aqueous solutions include $\mathrm{pH}$, temperature, ionic strength, and process contamination ${ }^{2}$.

Hydroxyapatite, $\left[\mathrm{Ca}_{5}\left(\mathrm{PO}_{4}\right)_{3} \mathrm{OH}, \mathrm{HAP}\right]$, is known as the main component of hard tissues i.e., bones and teeth. At low super-saturation, HAP directly crystallizes and grows in solution. On the other hand, at high super-saturation such as encountered in industrial water systems (i.e., cooling, boiler, desalination) it is generally agreed that the initially precipitated phase is an amorphous calcium phosphate, ACP. The mechanism of the precipitation of ACP from solution has not yet been fully established. In boiler water application, the predominant precipitated calcium phosphate is HAP.

Among the methods used to prevent calcium phosphate precipitation are acidification of the water and the use of polymeric or non-polymeric scale inhibitor. These methods prevent/retard markedly the precipitation and deposition of calcium phosphate scale on the heat exchanger surfaces. The acidification method has the disadvantage of exposing metal surface to a corrosive environment while the use of scale inhibitors seem promising since only very low concentrations are needed to extend the time required for the initiation of scale formation. Also, if acid addition shuts down, an increase in $\mathrm{pH}$ can cause immediate calcium phosphate precipitation $^{3}$.

During the last two decades dramatic advances have occurred in preventing the precipitation and deposition of calcium phosphate on various substrates i.e., heat exchanger, semi-permeable membrane, tooth enamel, fabric, ceramic, and equipment surfaces. As a result, synthetic polymers are finding increased applications in 
water treatment and home care products (i.e., laundry, dish washing). Imai et al. ${ }^{4}$, Amjad 5,6 and Amjad et al. ${ }^{7}$ in their studies on the evaluation of polymers of varying compositions concluded that both the functional group and ionic charge of the polymer play important roles in imparting inhibitory activity to polyme rs. For carboxylic acid containing polymers, it appears that precipitation inhibition is greatest for molecular weight of less than 20,000 with the optimum molecular weight being dependent on the particular polymer and scale forming salt being formed.

Thermal degradation of polymers is a well studied area. However, there is little information available of real value to a water technologist concerned with using low molecular weight polymers. Polymers used in high temperature operations i.e., boiler water treatment, thermal desalination, geothermal, etc., should be able to sustain high temperature and pressure environments normally associated with high temperature processes. Denman and Salutsky ${ }^{8}$ briefly examined the thermal stability of a sodium poly(methacrylate) under dry conditions and reported no significant change to $316^{\circ} \mathrm{C}$ but some charring at $371^{\circ} \mathrm{C}$. In 1982 Masler $^{9}$ investigated the thermal stability of several homo-polymers [i.e, poly(acrylic acid), P-AA; poly(methacrylic acid), P-MAA; poly(maleic acid), P-MA] used in boiler and thermal desalination. These polymers (before and after thermal treatment) were characterized by analytical techniques and also evaluated for their efficacy. It was demonstrated that P-AA, PMAA, and P-MA all underwent some degradation under the experimental conditions employed [pH $10.5,250^{\circ} \mathrm{C}$ (592 psig), $18 \mathrm{hr}$ ]. In terms of molecular weight loss, P-MAA lost slightly less molecular weight than P-AA which lost considerably less than P-MA. Additionally, P-AA and P-MAA had minimal performance changes whereas P-MA displayed a substantial loss in performance.

In the present work, we have used the pH-stat method to study the impact of thermal treatment on the performance of polymers as calcium phosphate inhibitors. The polymers tested include: (a) Homo -polymers of acrylic acid and maleic acid, (b) co-polymer i.e., acrylic acid:2acrylamido 2-methyl propane sulfonic acid; and (c) ter-polymers i.e., acrylic acid:2methylpropane sulfonic acid:sulfonated styrene and acrylic acid:2-acrylamido 2methylpropane sulfonic acid:t-butyl acrylamide. During this investigation various analytical techniques were employed to unders tand the impact of thermal treatment on the polymer architecture.

\section{EXPERIMENTAL}

Reagent grade chemicals, grade A glassware, and $\mathrm{CO}_{2}$-free distilled water were used. Stock solutions of potassium hydrogen phosphate and calcium chloride were prepared using distilled water and analyzed as described previously ${ }^{3}$. The inhibitors used were selected from commercial materials as shown in Table 1. All inhibitors solutions were prepared on a dry weight basis. The desired concentrations of inhibitors were obtained by dilution.

Sample Preparation: A solution of polymer was prepared containing $10 \%$ polymer (as active solids) at $\mathrm{pH} 10.5$ using sodium hydroxide to neutralize the polymer. Sodium sulfite was used as an oxygen scavenger. A known amount of polymer solution was retained for characterization and performance testing. The balance was charged to a stainless steel tube. The headspace was purged with nitrogen followed by tightening the fittings. The tube was then placed in the oven maintained at the required temperature [either at $150^{\circ} \mathrm{C}(84 \mathrm{psig})$ or $200^{\circ} \mathrm{C}$ (241 psig)]. After $20 \mathrm{hr}$, tubes were removed from the oven, cooled to room temperature, and solution transferred to vials for characterization and performance testing.

Polymer Characterization: The molecular weights of polymers were determined by GPC method according to the procedure described previously ${ }^{9}$. Nuclear magnetic resonance (NMR) spectra of polymers before and after thermal treatment were obtained on Brubaker AV-500 NMR spectrometer at $500.13 \mathrm{MHz}$ for spectra detection. Attenuated total reflectance infrared (FT-IR) of all samples were acquired on a Nicolet Magna 560 Fourier Transform Infrared (FT-IR) spectrometer, equipped with the Pike MIRackle.

Performance Test: All experiments were performed in a covered water-jacketed cell of $800 \mathrm{~mL}$ maintained at $50^{\circ} \mathrm{C}$. Sub-saturated solutions were prepared by placing known volumes of calcium chloride and potassium hydrogen phosphate. The total volume of the calcium phosphate solution was $600 \mathrm{~mL}$. Spontaneously precipitation of calcium phosphate solution was induced by raising the $\mathrm{pH}$ of the acidic solution with $0.10 \mathrm{M} \mathrm{NaOH}$ solution. The $\mathrm{pH}$ of the solution was maintained constant $(8.50 \pm 0.01)$ using $\mathrm{pH}$-stat apparatus as described previously ${ }^{3}$. Hydrogen ion 
measurements were made with a combination electrode equilibrated at the required temperature. The calcium phosphate solutions were continuously stirred with a Teflon ${ }^{\circledR}$ coated stirring bar at $~ 350$ revolutions per minute. Experiments involving inhibitors were performed by adding the inhibitor to the subsaturated calcium phosphate solution before inducing spontaneous precipitation. During the precipitation experiment samples were withdrawn, filtered through 0.22 micron filter paper and the filtrate analyzed for soluble phosphate by spectrophotometric method $^{3}$. Figure 1 shows the $\mathrm{pH}$-stat set-up used in the present study. The polymer performance was calculated according to the following equation:

$$
\text { \% Inhibition }=\frac{\left[\mathrm{PO}_{4}\right]_{\text {inh }}-\left[\mathrm{PO}_{4}\right]_{\text {fin }}}{\left[\mathrm{PO}_{4}\right]_{\text {ini }}-\left[\mathrm{PO}_{4}\right]_{\text {fin }}} \times 100
$$

Where :

$$
\begin{aligned}
{\left[\mathrm{PO}_{4}\right]_{\text {inh }}=} & \begin{array}{l}
\text { phosphate concentration in the } \\
\text { presence of inhibitor at } 22 \mathrm{hr}
\end{array} \\
{\left[\mathrm{PO}_{4}\right]_{\text {ini }}=} & \begin{array}{l}
\text { phosphate concentration in the } \\
\text { beginning of experiment at } 0 \mathrm{hr}
\end{array} \\
{\left[\mathrm{PO}_{4}\right]_{\text {fin }}=} & \begin{array}{l}
\text { phosphate concentration in the } \\
\text { absence of inhibitor at } 22 \mathrm{hr}
\end{array}
\end{aligned}
$$

Table 1. Polymers tested.

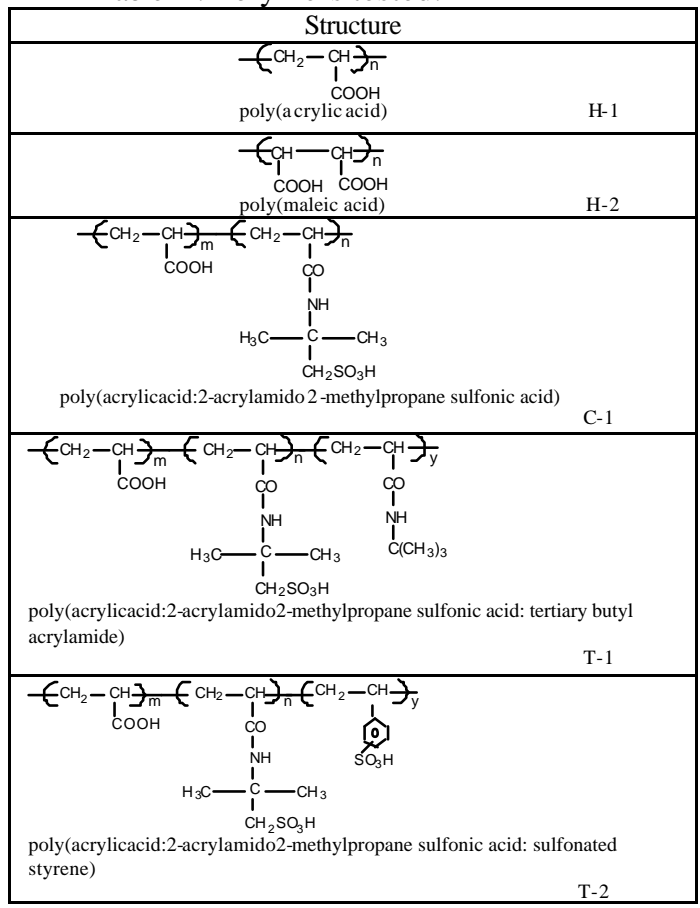

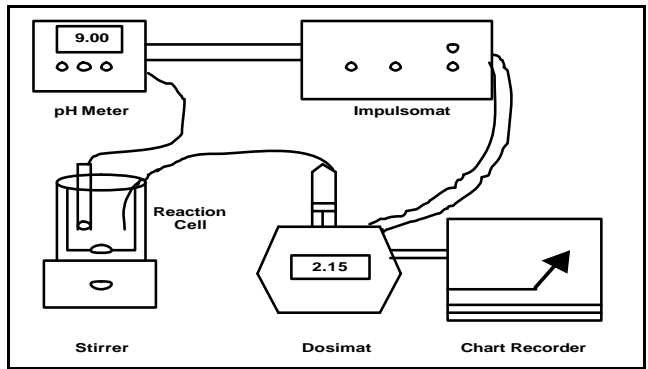

FIGURE 1. pH-stat set up.

\section{RESULTS AND DISCUSSION}

\section{Calcium Phosphate Inhibition}

A. Polymer Composition: The influence of heat treatment on the performance of polymers as calcium phosphate inhibitors was evaluated by conducting a series of experiments under standard test conditions $\left(\mathrm{Ca}=3.50 \mathrm{mM}, \mathrm{PO}_{4}=\right.$ $0.095 \mathrm{mM}, \mathrm{pH} 8.50,10 \mathrm{ppm}$ active polymer, $50^{\circ} \mathrm{C}, 22 \mathrm{hr}$ ). Figure 2 details the performance of various polymers under two test conditions (i.e., without heat treatment and with heat treatment or $200^{\circ} \mathrm{C}$ ).

It is evident from Figure 2 that exposure of polymer solutions to heat treatment have varying effect on polymer performance. For example, heat treatment has no negative impact on the performance of carboxylic acid containing poly(acrylic acid), H-1 and poly(maleic acid), $\mathrm{H}-$ 2 , indicating that there is no significant loss of carboxylic acid group. However, for the copolymer containing both carboxylic acid and sulfonic acid groups (i.e., C-1) the situation is markedly different as C-1 lost $\sim 90 \%$ inhibitory power. This suggests that SA component of the AA:SA co-polymer underwent essentially complete degradation leading to the formation of poly(acrylic acid). The poor performance $(<8 \%$ calcium phosphate inhibition) exhibited by thermally treated $\mathrm{C}-1$ is consistent with the performance of high $(>10,000)$ molecular weight $\mathrm{PAA}^{10}$.

Figure 2 also presents calcium phosphate inhibition performance data for the two terpolymers (i.e., T-1 and T-2). As shown in Table 1 the primarily difference between these two terpolymer compositions is the third monomer [i.e., t-bAM for T- 1 and sulfonated styrene (SS) forT2]. It is interesting to note that T-1 lost more inhibitory power $(\sim 73 \%)$ compared to $\sim 60 \%$ loss for T-2. The data clearly indicate that SS is more stable than the non-ionic monomer present in $\mathrm{T}$ 1. 
B. Polymer Dosage: To further demonstrate the impact of composition on performance after thermal treatment $\left(20 \mathrm{hr}\right.$ and $\left.200^{\circ} \mathrm{C}\right)$, a series of experiments were carried out with varying dosages of heat treated polymers. The three polymers selected were the C-1 co-polymer and the two ter-polymers (i.e., T-1 and T-2) which in the absence of thermal treatment (as shown in Figure 2) provide similar calcium phosphate inhibition.

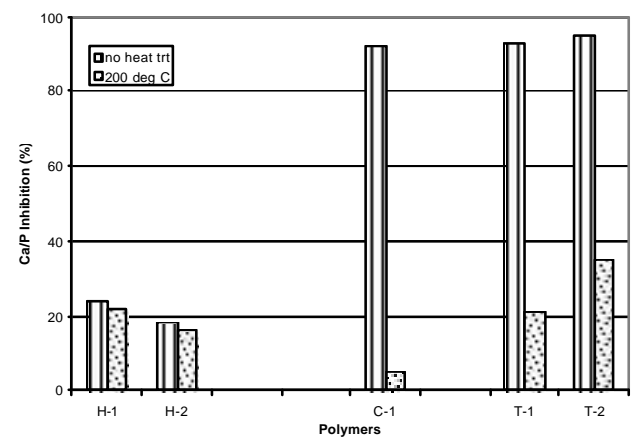

FIGURE 2. Effect of thermal treatment on the performance of polymers.

The results of thermal treatment shown in Figure 2 are amplified in Figure 3 wherein T-2 dramatically outperforms both the C-1 copolymer and the T-1 ter-polymer at the baseline $10 \mathrm{ppm}$ dosage and to a greater extent as the polymer dosage is increased from 10 to $20 \mathrm{ppm}$. The excellent performance shown by the heat treated T-2 may be attributed to the superior thermal stability of SS component.

C. Polymer Solution Temperature: Several experiments were performed to study the influence of different temperatures (i.e., $150^{\circ} \mathrm{C}$ and $200^{\circ} \mathrm{C}$ ) on the thermal stability of polymers. Figure 4 presents, the calcium phosphate inhibition data for the two ter-polymers before and after various levels of thermal treatment. It is evident from Figure 4 that temperature exhibits pronounced effect on the performance of polymers as calcium phosphate inhibitors. As shown in Figure 4, an increas e in the temperature from $150^{\circ} \mathrm{C}$ to $200^{\circ} \mathrm{C}$, results in further decrease in polymer performance. For example, \% calcium phosphate inhibition values obtained for $\mathrm{T} 1$ and $\mathrm{T}-2$ at $150^{\circ} \mathrm{C}$ are $89 \%$ and $94 \%$ respectively, compared to $22 \%$ and $38 \%$ obtained for T-1 and T-2 at $200^{\circ} \mathrm{C}$. This reflects about $75 \%$ decrease in performance of $\mathrm{T}-1$ versus $60 \%$ for $\mathrm{T}-2$. The relatively less loss in $\mathrm{T}$ 2 performance may be attributed to better stability of sulfonated styrene versus t-butyl acrylamide.

D. Iron Sensitivity: The influence of trace levels of metal ions (i.e., copper, zinc, manganese, iron, etc.) on the precipitation of scale forming salts has been the subject of numerous investigations ${ }^{11-13}$. It has been documented that polymer performance as calcium phosphate inhibitor is greatly affected by the presence of iron (III), aluminum, and cationic polymer flocculant ${ }^{14}$. In these cases polymer not only prevent calcium phosphate scale formation but must also act as a very good dispersant for iron oxide particles formed as a result of iron hydrolysis and/or corrosion products. Deposition of these unwanted materials must be minimized in order to prevent underdeposit corrosion and increasing pitting ${ }^{15}$.

In order to evaluate the impact of soluble iron (III) a series of precipitation experiments were carried out under standard test conditions. Figure 4 shows the effect of $1.0 \mathrm{ppm} F$ (III) on the performance of $\mathrm{T}-1$ and $\mathrm{T}-2$ polymers. By comparing the inhibition data in the presence and absence of iron (III) it is evident that presence of $1.0 \mathrm{ppm}$ iron (III) has an antagonistic effect on the inhibitory power of T-1 and T-2 polymers. The observed loss in performance in the presence of iron (III) may be attributed to decrease in polymer concentration in solution due to polymer adsorption on freshly precipitated iron hydroxide and/or iron chelation by polymer. As shown in Figure 4, compared to T-1, T-2 is a more effective calcium phosphate inhibitor in the presence of iron and after thermal treatment than $\mathrm{T}-1$.

\section{Molecular Weight}

In recent years, the influence of molecular weight (MW) on the performance of polymers as scale inhibitors has been the subject of intensive research. Amjad ${ }^{16-19}$ in studies on the evaluation of PAA in controlling the precipitation of $\mathrm{BaSO}_{4}$, $\mathrm{CaSO}_{4} .2 \mathrm{H}_{2} \mathrm{O}, \mathrm{CaHPO}_{4} .2 \mathrm{H}_{2} \mathrm{O}, \mathrm{Ca}_{5}\left(\mathrm{PO}_{4}\right)_{3} \mathrm{OH}$, and calcium phosphonate from aqueous solutions, reported that the MW of the polymer plays an important role in the inhibition of various scale forming salts. Results of these studies indicate that especially for P-AA, the optimum performance is obtained with $\sim 2000 \mathrm{MW}$.

In the present study GPC (gel permeation chromatography) was used to measure the molecular weight of the polymers tested. GPC gives relative molecular weights, not absolute molecular weights as in the case of primary methods such as vapor phase osmometry, 
membrane osmometry, and light scattering. However, by using the calibration standards with accurately known molecular weights, GPC yields molecular weights that match molecular weights determined by primary methods.

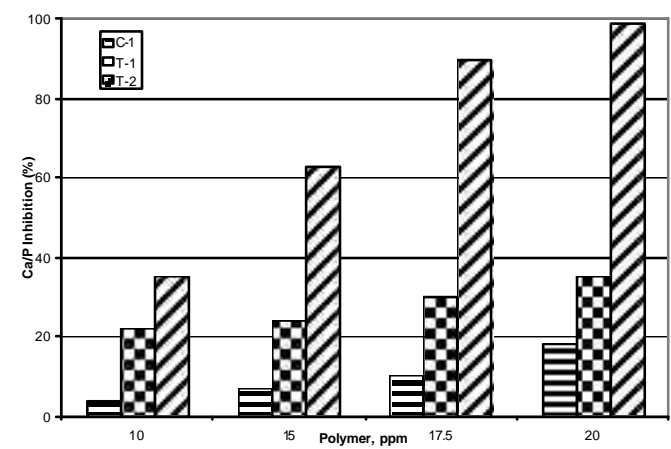

FIGURE 3. Effect of polymer dosage on the heat treated samples.

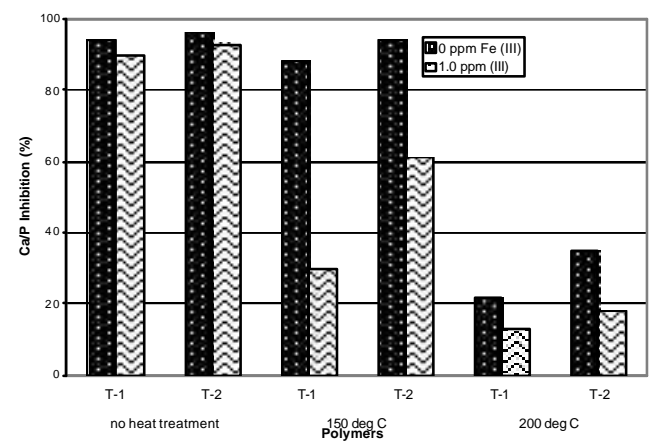

FIGURE 4. Effect of heat treatment on the performance of polymers.

It is well known that molecular weight of a polymer has profound effects on its performance in industrial water systems. For example, a low molecular weight $(2,000$ to 10,000$)$ polymers [e.g., poly(acrylic acid), acrylic acid:sulfonic, etc.], are effective scale control and dispersing agents whereas high $(>100,000)$ molecular weight polymers are poor scale control agents but may be effective flocculants.

All polymers degrade as a result of exposure to elevated temperature and pressure. The extent of degradation depends upon several factors including temperature, duration of heat treatment, and polymer architecture.

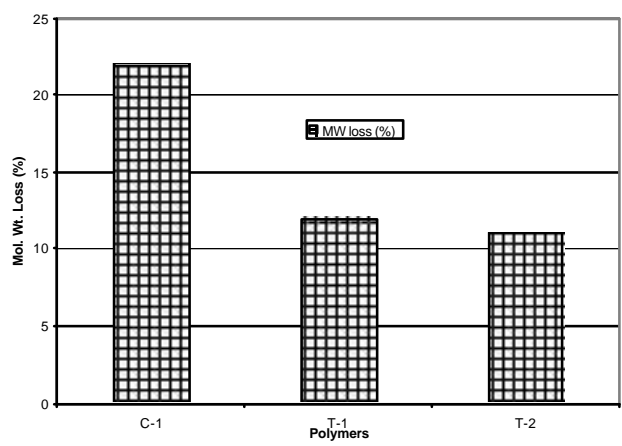

FIGURE 5. Plot of molecular weight loss for coand ter-polymers

The polymers used in the present study lost molecular weight as a result of their thermal treatment. Figure 5 depicts the "\% molecular weight loss" for homo, co- and ter-polymers. The data show that there is relatively small loss of molecular weight for homo -polymers (i.e., H1 and $\mathrm{H}-2$ ) after heating at $200{ }^{\mathrm{O}} \mathrm{C}$. Figure 5 also shows that ter-polymers are degraded to a lesser extent than co-polymer (C-1). For example, the molecular weight loss obtained for ter-polymers was $\sim 11 \%$ compared to $\sim 22 \%$ loss in the case of co-polymer.

\section{CONCLUSIONS}

The following conclusions may be drawn from the results presented here:

- All polymers tested in this study underwent thermal degradation but to a varying degree.

- The order in precipitation inhibition effectiveness is measured to be ter-polymer $>$ co-polymer $>$ homo -polymer.

- Polymer concentration is critical to the performance of calcium phosphate inhibiting polymers.

- The presence of iron (III) decreases the performance of calciu $\mathrm{m}$ phosphate inhibiting polymers.

- Polymers susceptible to thermal degradation experience both molecular weight and performance loss as the thermal stress is increased from $150^{\circ}$ to $200^{\circ} \mathrm{C}$.

\section{REFERENCES}

1. J. F. Wilkes, CORROSION/93 Paper No. 458, NACE, Houston, TX (1993).

2. Z. Amjad, Phos. Res. Bull. 9, 31 (1999).

3. Z. Amjad, in Calcium Phosphates in Biological and Industrial Systems, edited by 
Phosphorous Research Bulletin Vol. 20 (2006) pp. 165-170

Z. Amjad (Kluwer Academic Publishers, Boston, MA, 1998), Chap. 16 pp. 371-394.

4. T. Imai, T. Uchida, S. Ana, T. Tsuneki, CORROSION/89 Paper No. 423, NACE, Houston TX (1989).

5. Z. Amjad, J. Pugh, M. M. Reddy, in Water Soluble Polymers: Solution Properties and Applications, Edited by Z. Amjad (Kluwer Academic Publishers, Boston, MA, 1998), Chap. 11 pp. 131-148.

6. Z. Amjad, J. Hooley, J. Colloid Interface Sci. 111, 496 (1986).

7. Z. Amjad, J. Pugh, J. Zibrida, R. W. Zuhl, Mat. Perf.36, 32 (1997).

8. W. L. Denman and M. L. Salutsky, Proceedings of the $28^{\text {th }}$ International Water Conference, Pittsburgh, PA (1967).

9. W. F. Masler, $43^{\text {rd }}$ Annual Meeting, International Water Conference, Pittsburgh, PA (1982).
10. Z. Amjad, Can. J. Chem. 67, 850 (1988).

11. Z. Amjad, D. Butala, J. Pugh CORROSION/99, Paper No. 99118, NACE International, Houston, TX (1999).

12. S. K. Hamdona, R. B. Nasim, S. M. Hamza, Desalination 94, 69 (1993).

13. P. G. Koutsoukos, in Calcium Phosphates in Biological and Industrial Systems, edited by Z. Amjad (Kluwer Academic Publishers, Boston, MA, 1998), Chap. 17 pp. 145-172.

14. Z. Amjad, Phos. Res. Bull. 9, 115 (1999).

15. L. Perez, S. Kessler, in Water Soluble Polymers: Solution Properties and Applications, Edited by Z. Amjad (Kluwer Academic Publishers, Boston, MA, 1998), Chap. 12 pp. 149-1162.

16. Z. Amjad, Langmuir, 5, 1222 (1989).

17. Z. Amjad, Phos. Res. Bull. 5, 1 (1995).

18. Z. Amjad, Langmuir, 7, 2405 (1991).

19. Z. Amjad, Water Treatment, 9, 47 (1994). 